\title{
ethic @ \\ THE NEUROETHICS OF AGENCY: THE PROBLEM OF ATTRIBUTING MENTAL STATES TO PEOPLE WITH DISORDERS OF CONSCIOUSNESS
}

\author{
MARCO AZEVEDO 1 \\ (UNISINOS/Brasil) \\ BIANCA ANDRADE 2 \\ (UNISINOS/Brasil)
}

\begin{abstract}
How can we be certain that another creature is a conscious being? One path is to rely on introspective reports we can grasp in communication or observation of their behavior. Another path is to infer mentality and consciousness by means of markers tied to their intentional behavior, that is, agency. In this paper we will argue that even if agency is a marker of consciousness in several normal instances (paradigmatically, for mature and healthy human beings), it is not a good marker in several pathological instances, such as the blindsight case, the vegetative state, the akinetic mutism and the locked-in syndrome. If we are right, this can be of great utility in neuroethics; for those kinds of disorders of consciousness are not, after all, instances of complete absence of consciousness.

Keywords: Consciousness; Agency; Markers of consciousness; Disorders of consciousness; vegetative state; Akinetic mutism; Locked-in syndrome; Blindsight
\end{abstract}

\section{Introduction}

One of the problems for a theory of consciousness (or for any naturalist account on conscious states) is that, since consciousness is a private experience, the only evidence we can have to support any claim that some creature is conscious depends on indirect evidence about it. After all, we do not have any direct access to the experiential and conscious (if not experiential) content of the other's mental states. A consequence of this assumption seems to be that in order to attribute consciousness to a creature we need to rely on markers or signs that account for or warrant the claim that one is conscious or not. One plausible and influential account is called by Tim Bayne (2013) as the introspective account, or, in his words, the claim that the (only) legitimate markers of consciousness are introspective reports, that is, reports that one is in a certain type of (private, subjective) conscious state. Bayne contrasts this approach to an alternative 
view, namely, the account that agency is a better marker of consciousness. In his view, some introspective markers are actually best explained as truly agency markers, as information or reports that constitute evidence that one is in some kind of mental conscious activity when exhibits a piece of agential behavior.

The agency account has some frailties that were criticized mainly by the cognitive sciences. Bayne, in defense of the virtues of the approach, considers many criticisms from the cognitive scientists. He points out to the objections such as from Frith and colleagues (1999) that some pathological cases, such as the Blindsight patients (see below) shows that there can be goal-directed behavior without consciousness. Bayne's objection to this criticism claims that what the agency account requires is a robust correlation between consciousness and intentional agency, without requiring that all cases of intentional agency should be accompanied by consciousness. In our interpretation, his view is that agency can be considered as a sufficient condition for attributing consciousness, but no a necessary clause. Besides this, he claims that Blindsight patients are not prototypical examples of intentional behavior.

We agree that Bayne has good points, and, at first glance, attributing agency to a creature seems to be a good way to believe that someone is conscious. Nevertheless, the counterexamples from the cognitive scientists raise an important general question: is agency a general good and reliable marker for what Bayne calls creature conscience for every case, that is, in general? After all, it seems plausible, if not quite obvious, that agential behavior is connected to consciousness in mature human beings. Nevertheless, what seems to be agential behavior is observed not only in mature human beings, but also in infants, not to mention in animals; and some people attribute agential behavior to demented individuals and even to people that suffer from conscious disorders considered serious, such as vegetative states. Attributing consciousness to an individual deeply matters to ethical issues. Some philosophers consider that only conscious beings are subject of moral considerations on well-being and moral respect; if an individual is not conscious in a relevant way, their value is indifferent or matters only instrumentally, such as objects or things (see Kant). Nevertheless, consciousness is an "internal" state, a state that we cannot be directly or immediately acquainted with, except our own. In order to attribute consciousness to others we need to rely on markers, that is, on reliable signs that an individual is in these states. Is agency a reliable sign that an individual is conscious?

A first prior barrier to follow this path is on the concept (or concepts) of "agency"; after all, agency is a concept as diverse as the concept of 
consciousness itself. There are many accepted concepts of agency. One traditional approach relates agency, in a broad sense, to a capacity to act, but not only the to act upon the sake of acting, but to have intentionality to act - to consciously choose to act (Schlosser, 2019). This is especially useful for moral philosophers since a capacity to act intentionally permit us to attribute to the agent responsibility. Following this approach, agency involves a capacity to produce actions intentionally initiated. Nevertheless, this seems to impute too much; after all, sometimes an agent can display actions, and can be called responsible for them, without her intention being transparent even to the agent herself. Freud and psychoanalysts are well aware of this; it is not uncommon for agents to do things without being able to identify or report whether there was any previous conscious intention to do so. Or rather, we can even attribute intentionality to some individual agent without admitting that her intention was in fact conscious to the agent herself. Therefore, agency does not imply consciousness (Bayne, 2010, 2013). In effect, when we attribute agency (and responsibility) we are not necessarily claiming that the agent is conscious. Besides that, there is a second and harder problem, the question of "how much" we are aware of what one is doing, and if we or anybody can determine what precisely is happening "inside" another's brain even when we are confident that someone is acting intentionally and can be responsible for her action. This is hard, for, in several instances, consciousness can be taken to be a matter of degree. Sometimes this degree appears to be much lower that what we assume to be the normal state of healthy people, such as in cases of disorders of consciousness.

Before going forward, we do need to clarify what we are talking about - that is, what concept of agency we are going to use. Agency is both employed in philosophy of mind as a marker of consciousness and in ethics (and bioethics) to determine moral responsibility. The following perspectives on agency seem to be persuasively employed in these both domains of philosophy:

- The first-personal view. From this perspective, agents are seen as purposeful originators of deliberate action, moved by conscious purposes.

- The third-personal view. From this perspective, agents are entities whose behavior can be predicted and explained through the attribution to beliefs, desires, and rational choice (Wooldridge, 2014).

Combining these approaches, a plausible claim is that there is an intimate connection between agency and consciousness. Following the first 
approach, since agents are creatures moved by conscious purposes, attributing agency appears sufficient to attribute consciousness. Following the second, beliefs, desires and choices seem to be independent sufficient clauses for attributing agency. The union between these two approaches seems to lead us to a combination of necessary and sufficient conditions for assigning agency. In what follows, we intend to show that this conclusion is equivocal. Following the path of cognitive neuroscience, we will do this by addressing some medical examples that seems to contradict this conclusion.

\section{Access and phenomenal consciousness}

Before that, let us present some conceptual details. As became canonical in philosophy of mind, consider the distinction proposed by the philosopher Ned Block (1995) between two different notions of consciousness, access and phenomenal consciousness:

A state is access conscious (A-conscious) if, in virtue of one's having the state, a representation of its content is (1) inferentially promiscuous, that is, poised for use as a premise in reasoning, (2) poised for rational control of action, and (3) poised for rational control of speech.

Otherwise, phenomenal consciousness differs from access consciousness for being intrinsically experiential in character:

P-consciousness properties are experiential ones. P-
conscious states are experiential, that is, a state is P-
conscious if it has experiential properties. The totality of
the experiential properties of a state are "what it is like"
to have it. Moving from synonyms to examples, we have
P-conscious states when we see, hear, smell, taste, and
have pains. P-conscious properties include the
experiential properties of sensations, feelings, and
perceptions, but I would also include thoughts, desires,
and emotions.

In the task of considering agency as a marker of consciousness, a preliminary question should be: are we interested in which one of these two general kinds described above? Or are we interested in both, irrespectively? Introspective report is considered the gold standard marker for phenomenal or P-consciousness. After all, how could we attribute P-consciousness to a creature incapable to address introspective reports about her "internal" mental states? Or, how could we be certain about creature consciousness 
without such reliable markers of state consciousness? This is, nevertheless, the core of the problem we want to tackle here. In cases in which we simply do not have observable instances of agential behavior, we obviously cannot be present to instances of any kind of introspective reports (for even introspective reports are, in a sense, and agreeing with Bayne, also pieces of agential behavior). Should we simply conclude, hence, for any creature incapable to exhibit agential behavior or creatures that are incapable to make introspective reports that the right conclusion is that they cannot be P-conscious at all?

Consider again the two kinds of consciousness proposed by Block's approach. The approach is actually not two-fold by accident. Philosophers of mind seem to be inclined to think that access consciousness is a particularly important feature, if not essential, of any kind of consciousness, including $\mathrm{P}$-consciousness. And some even argue that access consciousness is all that matters to prove that a creature is conscious (Block, 1995; Boly, 2007). The reason is that A-consciousness seems to be intimately tied to agency, the widely recognized essential feature of mature behavior of rational creatures. Besides that, A-consciousness is an alleged state of mind connected to observable events, or states of mind connected to a view of agency in a third personal view.

There are a few problems worth discussing here. One, if agency can be truly tied to consciousness in a way that it can be taken as a good marker of it, we would be tempted to infer that whichever we observe a behavior that seems to be rationally controlled (intentionally), then there is some kind of consciousness involved, being it access or phenomenal. But, if agency is not a good general marker of consciousness, then, not being an agent might still leave room for conscious beings?

Because agency is so diverse in its meanings and because we cannot assume agency to be simple, a reason for doubt is that agency can both be a good marker of consciousness as it can be a bad one. If we take that firstpersonal view on agency above, that is "agents are purposeful originators of deliberate action, moved by conscious purpose", then we might assume that this "being" is conscious, as deliberative action stands for "selfgovernance" and for reasoning, in which we can assume that it needs someone that its truly invested in it, or, in other words, poised to that.

Nevertheless, if we take that "agents are entities whose behavior can be predicted and explained through the attribution to beliefs, desires, and rational choice", then there seems to be a lot more involved other than "deliberation". How can we be sure that there is a voluntary action connected to a form of A-consciousness "poised to" it? 


\section{Is agency a good general marker for consciousness: some counterexamples}

Consider, now, this:

The blind sighted case: Carl has a partial cortex lesion. During a medical appointment he is put in front of some obstacles and asked what he is seeing in front of him. Carl says he sees nothing. The doctor asks him to come and sit by his desk to talk, but, if Carl only moved forward, he would stumble into the obstacles placed there. Carl moves away from the obstacles and makes a perfect way to the desk without any incidents. Carl did not see nor known what was right in front of him, but, somehow, he was able to choose the best way.

Blindsight patients are truly a wonderful interrogation for state consciousness - after all, are they conscious or not of their surroundings? And more important, how can they access the information and deliberate if not "aware" of the process of decision-making? The agency account finds in blindsight patients a big enemy.

If a person that believes that agency, as it was conceptualized above, is a good mark of consciousness, what we should say about Carl? The observation that Carl does not bump, but deviates from objects that he introspectively denies that he is able to see, seems to be enough to infer that Carl has agential behavior and, therefore, consciousness, being it $P$ ou A-consciousness. Nevertheless, if we ask directly to Carl about it, he will be prone to expressly denies that he has any form of consciousness of those objects at all. The trick here lies underneath all this: since we, neither Carl, have any access to Carl's internal mental states, we seem to be fooled about what we observe (Carl idem), for it seems that we are really observing a kind of agential behavior.

So, from a first-person point of view, for Carl:

There is nothing that is like choosing an obstacle-free way.

But, for the third-person point of view:

There seems to have something that is like to choose an obstacle-free way.

Agency, in the case of blindsight patients is a two-way sort of thing they are somehow "conscious" as they are "not-conscious". It seems that Carl is not "poised to" in the sense that there is a conscious voluntary 
decision taking place, but, if Carl is not being "guided" by external forces, what else could lead Carl other than himself?

Of course, considering P-consciousness, there is something that is like being Carl - Carl, despite his diagnosis as a Blindsight patient, is a person with creature consciousness (in Bayne's sense) for he certainly exhibits several types of phenomenal consciousness that we recognize both from his observed agency behavior and from his introspective reports; Carl certainly exhibits some good level of A-consciousness. Blindsight, nevertheless, are patients usually impaired in the ability of the visual input-output cortex blind due to lesions in their striate cortex, also known as primary visual cortex or $\mathrm{V} 1$, to respond to visual stimuli that they do not consciously see (Berkowitz, 2017). If it is true that we can somehow say that Carl is conscious (even if his creature consciousness is somehow deficient), then we must be able to state what kind of consciousness Carl has. However, even if it is true that, in Carl's case, conscience and agency work together, this is false at least in the typical cases of the mysterious agential behavior that Carl exhibits when he avoids hitting objects without perceiving such things ${ }^{3}$.

\section{The challenge of vegetative state for agency as a marker for consciousness}

A test that seems useful in medicine for asserting that one is aware, and conscious, is submit patients to tests of command following. A suggestive study about vegetative state and command following was published by Colin Klein (2017) and might contain some answers towards the discussion of agency as a marker of consciousness. The basic idea was to put a variety of patients correctly diagnosed as being in a vegetative state and search for responses to commands that would (in theory) require intentional agency.

The study in question seems to show that some vegetative patients are capable of command following, as fMRI images seem to suggest (Klein, 2017). According to Klein, the findings suggest, at first glance, that individuals of some kinds of vegetative states are, in fact, conscious in some way. Nevertheless, this suggestion is, in his own words "both scientifically and philosophically controversial". Klein claims actually that the evidence in the study that some patients show signs of positive responses when it comes to command following does not automatically place them in a spectrum of intentional agents. This goes exactly on the path that we would expect as a bystander of a vegetative state person. Persons in vegetative 
state paradigmatically do not exhibit intentional reactions, spontaneous or evinced by orders - how could we give to those individuals an agent status?

If there is something that is like to be in a vegetative state, this is hidden so far from us in such a way that we cannot imagine what it is like to be them. The studies, nevertheless, have shown that some autonomous and automatic responses of some parts of the brain are still active in these patients. Does this mean that there is some intentional agency taking place? Given our state of ignorance about the minute details about the functioning of our brains, it is unlikely that we will obtain information in the short term that will allow us to determine whether an individual with serious disorders of consciousness, such as the vegetative state, is or is not capable of exhibit at least some, albeit incomplete, intentional activities. Given this, the most we can infer is based on what we can clinically observe: the absence of intelligible and purposeful observable behaviors, a sort of state that resemble creatures endowed with vegetative souls (in the ancient Aristotelian sense).

This is compatible with a common sensical belief. Sometimes we also behave in a way that we assimilate to behaviors not backed by any conscious intentional activities. For instance, it is well-known that we can respond to certain stimuli or orders by a pure arch-reflex mechanism. Those are neurological reactions that we do not classify as "behavioral intended responses" (Boly, 2007). Since we cannot present introspective reports about them, we take them as alien form our consciousness. Consider that you are cooking and, not being careful enough, reach out your hand and get burned - the response is familiar and quite prompt: you immediately pull your hand away from the source of fire and only after the action you figure it out what you did. We plausibly could classify the behavior as an action, and maybe an intentional action (after all, is not the intention of the "reaction" to prevent us from getting burned?). Anyway, we usually classify those kinds of reactions as "instinctive" or simply "mechanical". Common sense seems to be right; because you might think you wanted to do that this does not mean that this is the best explanation. Pulling your hand away is, as we know today given the best neurological evidence, an automatic response that occurs due to a specific defense mechanism named "reflex arc" (Berkowitz, 2017). You actually pull your hand fast enough to prevent damage to his arm, but the conscious description of what happened is an afterthought produced after your brain was informed by the perceptions of about has happened. There is no decision-making or intentional agency in here. Today it is preposterous to say that people might have intentionality upon states that are "automatic" responses (Klein, 2017). By analogy, this is also most accepted explanation about what is seen in people with 
vegetative states. Since their "actions" are in fact unintentional pure neurological "reactions", people in vegetative states are not taken by the scientists and clinicians as true agents.

Nevertheless, absence of intentional agency does not rule out that there can be something that is like to be in a vegetative state (Boly, 2007), as it also seems to apply to any other disorder that fails the requirements for intentional agency. What is this state like or what type of Pconsciousness they have left is a hard question for which we still do not have complete and cogent answers?

Arguing for a view different from the traditional medical view, Will Davies and Neil Levy (2017) argue in favor of vegetative patients showing signs of "intentional and voluntary" behavior, in direct opposition also to Colin Klein's (2017) work. The main point of their paper was to prove that these patients - vegetative state persons - did have some "kind" of consciousness.

The main evidence that Davies and Levy take into account in their argument come from fMRI studies; and they are very persuasive. There is, in fact, some "type" of answer showed by the individuals stricken by vegetative states in the fMRI studies.

To construct their argument, Davies and Levy (2017) make use of the following assumptions:

Command Following: Command following is a marker of intentional agency, i.e., evidence for command following provides strong evidence for the presence of intentional agency.

Agency: Intentional agency is a marker of consciousness, i.e., evidence for intentional agency provides strong evidence for the presence of consciousness.

These assumptions imply that command following implies intentional agency (by definition). But in doing so, the authors beg the question, and the article seems to have a lack of neutrality when it comes to proving its own point. There is no doubt that command following and agency can be connected - this is, in fact, true in some cases, but, in others, the bound between command following and intentional agency does not necessarily hold nor are so strong. The connection, hence, is not conceptual, but empirical. If we assume that command following necessarily implies intentional agency, we will have some problems when we consider the case of serious disorders of consciousness such as vegetative states.

This is true, first, because spotting command following is not always so clear. Second, because we do not have direct access to mental content, 
we might be misled to think that there is intentional agency when, in fact, there isn't (Boly, 2007; Klein, 2017). In fact, command following could lack in some instances one essential character of agency: voluntary behavior. Animals can follow commands and we do not necessarily attribute to them the capacity of voluntary action.

But because command following implies that the subject is being told what to do, we can be misled when individuals are only reacting by mere automaticity and not by voluntary agency behavior (Klein, 2017).

\section{The awkward cases of akinetic mutism and the locked-in syndrome}

Consider now this example:

The case of akinetic mutism: David lies still on the bed. He does not move voluntary and he does not talk much. Many of his responses when there are any - are simple and monosyllabic. Nevertheless, he still can talk, he only does not do so. He feels hungry and can eat alone, but, if not fed, he will not ask for food. Off-repeated commands is followed by David, but in a slow, incomplete way, as he lacks something about doing this. David does not have any muscular problems either and "shows" sign of being a person of "normal" intelligence.

Fortunately, akinetic mutism is a rare disease, but it presents itself on several different levels. There are less severe forms - in which the patient is somewhat like David, responsive - and severe cases, in which the patient is not responsive at all, remaining silent and still - such cases often have poor prognosis. To understand akinetic mutism, try to imagine what it is like to have "nothing that is like" being them. This is, for sure, a hard - if not impossible exercise. Colin Klein described these patients as: "When asked about his private thoughts he just said 'that's all right', 'I think of nothing', 'I don't want anything'. When asked about the content of his thoughts, the patient claimed he had none, suggesting a state of mental emptiness'" (Engelborghs et al. [2000] p. 1763; Klein, 2017).

Although akinetic mutism might have more than a fair couple of explanations, this is not important for us here. The important question here is to figure it out David's own experiences - if there is something that is like being David and, if not, what is there to learn about what agency represents to David.

We seem to be able to perceive David conscious in a way. David has input-output - he responds to questions, but, on the other hand, we cannot claim David to have intention, and this is the challenge upon claiming David 
as an agent. If David has nothing that is like being him, or, in other words, if he lacks phenomenal consciousness, we could also ask ourselves what it is like to have access consciousness without phenomenal consciousness whatsoever. David actually seems to lack any sort of qualitative mental character.

The argument starts to point out to a much weaker relationship between consciousness and agency then prior expected. The bound between these two depends on how intentionality takes place - note mere stimuli. Even if in general agency does not seem to be present in individuals that lack some kinds of P-consciousness or A-consciousness, consciousness seems to be present without agency in these strange clinical circumstances such as akinetic mutism.

The trick part about all of this is how consciousness can be disguised. Imagine this:

The locked-in syndrome case: Susan is a 30-year-old woman who has suffered a severe brain injury and woke up in a hospital bed without being able to move or speak. She feels everything - pain, emotions, she has thoughts and can reason about things. The doctors assumed she was in a coma, so, most of the time, people do not refer to her as a "full person" or even talk to her before procedures. Susan hears everything, and hopes she gets better soon, but she has no way to communicate that she can understand what is going on.

Of all disorders of consciousness, locked-in syndrome holds a very peculiar and interesting status for philosophy. This is a disorder in which a conscious, mute patient, is completely paralyzed apart from some form of eye movement, usually as a result of an infarct in the ventral pons. Such patients are often assumed to be in coma and as a result may be distressed by inappropriate conversation around the bedside. It is a shell with a pearl inside - but how to make sense of the pearl if we just cannot see it?

First, let us begin by assuming here that, as for phenomenal consciousness, locked-in syndrome patients possess this. If we can imagine what it is like to be in a locked-in syndrome, we must agree that there is something that is like to be in a locked-in syndrome. There are perceptions, emotions, feelings attached to the being - they are just locked in there. In consequence:

There is something that is like to be Susan.

In fact, neurologists think of locked-in syndrome patients as being endowed with full cognition and mental capacities that cannot interact with 
the world - but everything other than that is right where it was supposed to be. It is very easy to imagine a locked-in individual endowed with full Pconsciousness - but how to prove that they are also endowed with Aconsciousness? How those creatures could have mental conscious stated poised for use as premises in reasonings, for rational control of action, or for rational control of speech?

If we really can imagine what is it like to be in a locked-in syndrome state, then consciousness cannot have nothing essentially to do with muscular voluntary responses. Actions, that is, those events that begin with these more "basic actions" such as muscular voluntary responses may be an accurate way to prove consciousness in normal cases, but it has nothing to do with what we think to be P-consciousness conceptually, and maybe also with A-consciousness (as it is shown by these individuals locked-in their own skulls). The awkward examples we mention above show us that it is plainly possible to lack the ability to respond with muscular activity (agency) and still have consciousness. Even more familiar examples can show us that this is perfectly possible (think of a person in a wheelchair, paralyzed from the neck down, cruelly abandoned somewhere without the help of anyone).

Like the tetraplegics, locked-in syndrome individuals seem to be Pconscious for us; and we also think they can have A-conscious states, even though these states cannot be poised for use in actions and speech. It seems plausible, hence, that people like this can use their reasonings and can form intentions, and plausibly they can have desires and wills, but the lack of a full and healthy bound between mind and their active body lend them to serious mental disability that eventually led them to succumb to mental inactivity. Nevertheless, even if this is the clinical natural outcome of the disorder, the conclusion we can draw is that in them mind and agency are not essentially connected as supposed should be.

\section{Conclusion}

In this paper, we argued that agency and consciousness are not tied in all instances. This is a conclusion of interest for neuroethics, since the subjects of consciousness and agency are in the core of this new philosophical discipline. In support of this claim, we presented some curious but paradigmatical clinical cases of disorders of consciousness that, even being "disorders", are considered deficient forms, but still forms of conscious activity at all. In consequence, the claim that agency is a good marker of consciousness cannot be sustained fully, or at least in a general or universal way. Although they seem to relate to each another, if is plainly possible that we can have conscious individuals that lack agency as well as individuals that seems to be have kinds of "agency", but lack phenomenal, 
and plausibly also access consciousness. If agency is a marker of consciousness, it does not seem to sustain this role alone. There are, hence, instances in which agency has a lower sensibility and specificity for consciousness. In these instances, the very question about what it is like to be them is hard, and since we do not have from them the help of introspective reports, and being agency a poor marker of the presence of an active mind, we should look for answers about this question elsewhere. 


\section{Notas}

1 Professor do Programa de Pós-Graduação em Filosofia da Universidade do Vale do Rio dos Sinos (UNISINOS), São Leopoldo, Rio Grande do Sul (R.S). ORCID-iD: https://orcid.org/0000-0003-4313-2612; e-mail: mazevedogtalk@gmail.com

2 Doutoranda na Universidade do Vale do Rio dos Sinos (UNISINOS), São Leopoldo, Rio Grande do Sul (R.S). ORCID-iD: https://orcid.org/0000-0003-1167-0563; email: biancaandrade@msn.com

3 Beyne (2013) is not convinced that the blindsight case can be classified as an instance of full intentional action. Hence, following Bayne, one may concede that the example of the blindsight case is a defective case of what is an intentional action and still claim that agency is a "good" marker of consciousness for the "normal" cases. Nevertheless, if we are correct, it should lead us to think about the nature of these states that we understand as conscious. Thanks for the comment of an anonymous referee of the journal. 


\section{References}

BAYNE, T. Agency as a marker of consciousness. In: CLARK, Andy; KIVERSTEIN, Julian \& VIERKANT, Tillmann. Decomposing the will. Oxford: Oxford University Press, 2013.

BAYNE, T.; SHEA, N. The vegetative state and the science of consciousness. British Journal of Philosophy of Science, 61, 2010: 459-484.

BAYNE, T. HOHWY, J. OWEN. A. M. Are there levels of consciousness? Trends in cognitive sciences, 20(6), 2016.

BERKOWITZ, Aaron L. Lange clinical neurology and neuroanatomy: A Location-based approach. $1^{\text {st }}$ Edition. Kindle Edition. Lange, 2017.

BLOCK. N. On a confusion about a function of consciousness. Behavioral and Brain sciences, 18(2), 1995: 227-287.

BLOCK. N. Consciousness. In: GREGORY, R. Ed. Oxford Companion to the mind. Second Edition, 2004.

BOLY, M. When thoughts become action: An fMRI paradigm to study volitional brain activity in non-communicative brain injured patients. Neuroimage, 36(3), 2007: 979-92.

BURGE, T. Foundations of mind. Philosophical essays. Volume 2. Oxford: Clarendon Press, 2007.

FRITH, C., PERRY, R., \& LUMER, E. The neural correlates of conscious experience: An experimental framework. Trends in the Cognitive Sciences 3, 1999: 105-114.

KLEIN, C. Consciousness, intention, and command following in vegetative state. The British Journal for Philosophy of Science, 68(1), 2017: 27-54.

LEVY, N. The value of consciousness. Journal of Consciousness Studies, 21(1-2), 2014: 127-138.

NAGEL, T. What is it like to be a bat? The Philosophical Review LXXXIII, 4, 1974: 435-50.

SCHLOSSER, M. Agency. The Stanford Encyclopedia of Philosophy (Winter 2019 Edition), Edward N. Zalta (ed.), URL = <https://plato.stanford.edu/archives/win2019/entries/agency/>. 
WOOLDRIDGE, W. MILLICAN, P. Them and us: Autonomous agents in vivo and in silico. In: BALTAG, A \& SMETS, S. (eds.). Johan van Benthem on logic and information dynamics. Outstanding Contributions to Logic 5, Springer-Verlag, 2014.

Received/Recebido: $16 / 03 / 21$ Approved/Aprovado: 06/04/21 